(RESEARCH ARTICLE)

\title{
Calcified nodule formation by dental pulp cells derived from rats after subcutaneous injection of an immunosuppressant
}

\author{
Masataka Yoshikawa*, Ayano Miyamoto, Ryoichi Ikezawa, Hitomi Nakama, Ikuo Nishikawa and Hiroshi \\ Maeda
}

Department of Endodontics, Faculty of Dentistry, Osaka Dental University 5-17, Otemae 1-Chome, Chuo-ku, 540-0008 Osaka, Japan.

Publication history: Received on 26 October 2020; revised on 03 November 2020; accepted on 04 November 2020

Article DOI: https://doi.org/10.30574/wjarr.2020.8.2.0401

\begin{abstract}
Introduction: The purpose of this study was to assess the significant proliferation of dental pulp-derived stem cells in vitro from rats with the systemic administration of immunosuppressant in subcutis. There must be a sufficient number of stem cells for tooth regeneration. However, number of mesenchymal stem cells in the dental pulp tissue is a small. Then, the proliferation of stem cells must be accelerated for hard tissue formation. The subcutaneous injection of the immunosuppressant would enhance the hard tissue forming ability of dental pulp cells of rat. It was hypothesized in this study that differentiation of stem cells into blasts would be effectively promoted by suppression of the systemic immune response.
\end{abstract}

Materials and methods: The dental pulp cells of rats with immunosuppressant injection subcutaneously were cultured with or without addition of the immunosuppressant in the medium containing dexamethasone for calcified nodule formation. $\mathrm{Ca}^{2+}$ by decalcification of calcified nodules were quantitatively analysed. Statistical comparisons between the quantities of $\mathrm{Ca}^{2+}$ were performed using two-way unrepeated ANOVA followed by post hoc analysis with Tukey-Kramer test. Differences of $p<0.01$ were considered significant.

Results: The proliferation and differentiation of stem cells among dental pulp cells was inhibited by the presence of immunosuppressive agents in the culture medium. However, stem cells obtained from rats after systemic administration of an immunosuppressive agent exhibited a high ability to form calcified nodules.

Conclusions: To promote proliferation and differentiation of stem cells, systemic administration of an immunosuppressant to individuals prior to harvesting stem cells would be recommended.

Keywords: In Vitro; Stem Cells; Dental Pulp Cells; Dentine Regeneration; Mizoribine

\section{Introduction}

Mesenchymal stem cells (MSCs) are necessary for the regeneration of bone [1]. The components of bone are similar to those of dentine [2]. Therefore, many basic experiments on tooth regeneration have been performed using cells obtained from bone marrow [3]. However, in dentistry, collection of stem cells for tooth regeneration from bone marrow by puncture should be avoided because of the marked psychological and physical burden on the patient. The pulp of a permanent tooth being extracted for orthodontic purposes or from deciduous teeth may be useful as a cell source of odontoblasts. Primary culture of odontoblasts was previously reported [4], but the isolation and culture of odontoblasts

\footnotetext{
* Corresponding author: Masataka Yoshikawa

Department of Endodontics, Faculty of Dentistry, Osaka Dental University 5-17, Otemae 1-Chome, Chuo-ku, 540-0008 Osaka, Japan. Copyright $(2020$ Author(s) retain the copyright of this article. This article is published under the terms of the Creative Commons Attribution Liscense 4.0.
} 
is difficult. It is important to establish a simple method for the rapid proliferation of MSCs in dental pulp and subsequent differentiation into odontoblasts [5].

Pulp tissue or tooth germ may be used as a source of stem cells for the regeneration of teeth and other tissues [6, 7]. However, the number of stem cells contained in the tooth pulp is small [8]. Ectopic bone formation by MSCs was reportedly observed in immunodeficient mice, whereas no ectopic bone was formed in mice with normal immune function [9]. MSCs may control immunocompetent cells, represented by T cells. It has been reported that MSCs suppress T cell proliferation [10], whereas bone regeneration was inhibited by T cells [11]. The ability of mouse bone marrow-derived MSCs to differentiate into osteoblasts was suppressed by T-cells [12].

It was hypothesized in this study that differentiation of stem cells into osteoblasts can be effectively promoted by suppression of the systemic immune response. Therefore, in this in vitro study, mizoribine (MZR) was used as an immunosuppressant. MZR, an imidazole nucleoside, selectively inhibits inosine monophosphate synthetase and guanosine monophosphate synthetase [13]. MZR inhibits both humoral and cellular immunity by selectively blocking the proliferation of lymphocytes [14]. The subcutaneous injection of MZR was hypothesized to improve the hard tissueforming ability of rat dental pulp cells (rDPCs) by systemically suppressing the immune response. Quantitative analysis of calcified nodule formation by culturing the cells was performed to confirm the effects of MZR.

\section{Material and methods}

\subsection{Animals}

This study was performed at the Laboratory Animal Facilities at the Institute of Dental Research under the Guidelines for Animal Experimentation of Osaka Dental University. Regarding the use and care of the animals, the Animal Welfare Committee of Osaka Dental University approved the experimental procedures. Animal experiments in this study had been complied with the ARRIVE guidelines and been carried out in accordance with the National Institutes of Health guide for the care and use of Laboratory animals (NIH Publications No. 8023, revised 1978).

Six 6-week-old male Fischer 344/N Slc rats (Japan SLC, Inc., Shizuoka, Japan) were used in this study. They were housed in standard rat cages with free access to dry pellets and water with unrestricted movement at all times during this experiment. In each of 3 cages, 2 of rats were respectively kept for 2 weeks.

\subsection{Subcutaneous injection of MZR solution}

A solution of immunosuppressant for subcutaneous injection was prepared. MZR (5-Hydroxy-1- $\beta$-D-ribofuranosyl- $1 H$ imidazole-4-carboxamide: FUJIFILM Wako Pure Chemical Corp., Osaka, Japan) was dissolved in ultra-pure water at 1 $\mathrm{mg} / \mathrm{ml}$. Dorsal subcutaneous injection of $1 \mathrm{ml}$ of MZR was performed seven times every 2 days to 3 rats under general anesthesia by inhalation of isoflurane (Forane ${ }^{\circledR}$; Abbott Japan Co. Ltd., Tokyo, Japan). The other 3 rats without injection were used as a control.

\subsection{Isolation and preparation of rDPC suspension}

After euthanasia by overdose of isoflurane, incisors were removed from the transected mandibular bone. After being soaked in povidone iodine solution (Povidone-Iodine Solution 10\% ${ }^{\circledR}$ : Meiji Seika Pharma Co., Ltd., Tokyo, Japan) for several seconds, they were washed three times in phosphate-buffered solution without $\mathrm{Ca}^{2+}$ and $\mathrm{Mg}^{2+}(\mathrm{PBS}(-)$; FUJIFILM Wako Pure Chemical Corp., Osaka, Japan). Dental pulp tissue in the root canal was removed using a \#30 K-type file (KaVo Dental Systems Japan Co., Ltd.). For digestion, the pulp tissue was placed in a trypsin-EDTA solution $(0.25 \mathrm{w} / \mathrm{v} \%$ trypsin and $1 \mathrm{mmol} / \mathrm{l}$ EDTA-4Na solution; FUJIFILM Wako Pure Chemical Corp.) in a multi-well culture plate (6-well: BD Biosciences, MA, USA) and kept in an incubator $\left(5 \% \mathrm{CO}_{2}\right.$ and $95 \%$ relative humidity at $\left.37^{\circ} \mathrm{C}\right)$ for 30 minutes. Culture medium (MEM: Eagle's minimal essential medium: FUJIFILM Wako Pure Chemical Corp.) containing 15\% fetal bovine serum (FBS; SAFC Biosciences, Inc., KS, USA) and antibiotics (100 U/ml of penicillin, $100 \mathrm{mg} / \mathrm{ml}$ of streptomycin and $0.25 \mathrm{mg} / \mathrm{ml}$ of amphotericin B; Sigma-Aldrich Co. LLC., MO, USA) was prepared. The dispersed rDPCs were passed through a cell strainer (Pore size: $40 \mu \mathrm{m}$, Corning Inc., NY, USA) and suspended in MEM in a centrifuge tube (50 ml; CORNING Inc.). The cells were centrifuged in MEM 3 times at $120 \times \mathrm{g}$ for 10 minutes at $4^{\circ} \mathrm{C}$. Then, rDPCs suspended in $18 \mathrm{ml}$ of MEM were divided into 6 aliquots of $3 \mathrm{ml}$ each and poured into culture flasks (T-25; CORNING Inc.) for primary culture. They were kept in an incubator in $5 \% \mathrm{CO}_{2}$ and $95 \%$ relative humidity at $37^{\circ} \mathrm{C}$ for the primary culture. MEM was exchanged 3 times per a week. Confluent rDPCs after 7 weeks in T-25 were released from the bottom of well using a $0.05 \% \mathrm{w} / \mathrm{v}$ trypsin and $0.53 \mathrm{mmol} / \mathrm{l}$ EDTA-4Na solution (FUJIFILM Wako Pure Chemical Corp.), and collected in 
centrifuge tubes after trypsinization. The harvested rDPCs were washed by centrifugation at $120 \times \mathrm{g}$ for 5 minutes at $4^{\circ} \mathrm{C}$ and re-suspended in MEM at $0.5 \times 10^{5}$ cells $/ \mathrm{ml}$.

\subsection{The subculture of rDPCs for calcified nodule formation}

Calcified nodule formation by cultured rDPCs from rats with and without subcutaneous injection of MZR was estimated in multi-well culture plates (6-well culture plate; CORNING Inc.). In each well of the 6-well culture plates, $2 \mathrm{ml}$ of cell suspension containing $1 \times 10^{5}$ of rDPCs was poured and the cells were cultured for 11 days. To induce calcified nodule formation by rDPCs in each well, $20 \mu \mathrm{l}$ each of $10 \mathrm{nmol}$ dexamethasone (Dex: Sigma-Aldrich Co. LLC.,), $1 \mathrm{mmol} \beta$ glycerophosphate ( $\beta$-GP; EMD Biosciences, Inc., CA, USA) and $82 \mu \mathrm{g} / \mathrm{ml}$ ascorbic acid (Vc; Sigma-Aldrich Co. LLC.) was added to the MEM. MEM was exchanged three times each week. Calcified nodule formation was confirmed under a phase-contrast inverted microscope.

\subsection{Measurement of the alkaline phosphatase activity level in rDPC culture}

The buffer solution (TNE: pH 7.4) consisted of 1 mmol of 2-Amino-2-(hydroxymethyl)-1, 3-propanediol hydrochloride (FUJIFILM Wako Pure Chemical Corp.), $0.1 \mathrm{mmol}$ of ethylene-di-amine tetra-acetic acid tetra-sodium tetra-hydrate salt (FUJIFILM Wako Pure Chemical Corp.) and $10 \mathrm{mmol}$ of sodium chloride (FUJIFILM Wako Pure Chemical Corp.). All procedures for analysis of alkaline phosphatase (ALP) activity were performed at 3 to $6^{\circ} \mathrm{C}$.

Each cell layer with deposited calcified nodules in the wells was scraped after the addition of $500 \mu \mathrm{l}$ of TNE buffer using a cell scraper (AGC Techno Glass Co., Ltd., Shizuoka, Japan) and was collected in a 1.5-ml microtube. An additional $500 \mu 1$ of TNE buffer was poured into each well and transferred into the tube. The cells in TNE buffer solution were sonicated (BIORUPTOR UCW-201; Tosho Denki Co., Ltd., Yokohama, Japan) for 30 seconds. For DNA measurement, $20 \mu \mathrm{l}$ of the supernatants was mixed with $200 \mu \mathrm{l}$ of Hoechst 33258 (FUJIFILM Wako Pure Chemical Corp.) at $2.5 \mu \mathrm{g} / \mathrm{ml}$. The amount of DNA was measured using a fluorescence-spectrum photometer (Spectra-Max M5; Molecular Devices, Inc., CA, USA) at an excitation wavelength of $355 \mathrm{~nm}$ and fluorescence emission at $460 \mathrm{~nm}$. To obtain a calibration curve, salmon sperm deoxyribonucleic acid (DNA; Life Technologies Inc., CA, USA) was diluted at 5, 10, 25, 50 and $100 \mu \mathrm{g} / \mathrm{ml}$ in TNE solution. After DNA analysis, the sonicated cell suspension was centrifuged at 15,000 $\times \mathrm{g}$ for 3 minutes. To measure ALP, $100 \mu \mathrm{l}$ of $p$-nitrophenyl phosphate (PNP: Thermo Fisher Scientific Inc., MA, USA) as a substrate was added to $20 \mu \mathrm{l}$ of the supernatant and incubated at $37^{\circ} \mathrm{C}$ for 30 minutes. To stop the reaction, $100 \mu \mathrm{l}$ of sodium hydroxide at a concentration of $0.2 \mathrm{~mol}$ was added. The amount of $p$-nitrophenol was measured using the absorbance at a wavelength of $405 \mathrm{~nm}$ with Spectra-Max M5. To obtain a calibration curve, $p$-nitrophenol at $0.025 \mu \mathrm{mol}$ was used as a positive control and TNE solution was used as a negative control.

The ALP activity calculated by the ALP / DNA ratio is presented as $\mu$ mol of $p$-nitrophenol released after 30 minutes at $37^{\circ} \mathrm{C}$. The results are presented as the mean \pm standard error. Statistical comparisons between the mean values were performed using two-way unrepeated ANOVA followed by post hoc analysis using the Tukey-Kramer test. Differences of $p<0.01$ were considered significant.

\subsection{Quantitative analysis of $\mathrm{Ca}^{2+}$ from calcified nodules in rDPC culture}

The amount of calcified nodules aggregated in MEM was expressed as a quantity of $\mathrm{Ca}^{2+}$ after decalcification. After ALP analysis, the samples in a $1.5-\mathrm{ml}$ micro-tube were centrifuged at $15,000 \times \mathrm{g}$ for 10 minutes. The supernatant was removed and the precipitate was decalcified in $500 \mu \mathrm{l}$ of a $20 \%$ formic acid solution for 7 days.

The amount of $\mathrm{Ca}^{2+}$ in the precipitate was measured using a commercially available kit (Calcium E-test Wako ${ }^{\circledR}$ : FUJIFILM Wako Pure Chemical Corp.). The outline of the assay is as follows: A mono-ethanolamine buffer (pH 12) and methyl xylenol blue (MXB) as the coloring reagent were included in the kit. After centrifugation, $50 \mu \mathrm{l}$ of the supernatant was added to $2 \mathrm{ml}$ of the buffer solution. Methyl xylenol blue binds to $\mathrm{Ca}^{2+}$ under alkaline conditions and the reactant turns blue. Then, the $\mathrm{Ca}^{2+}$ produced in the cell culture was measured by the absorbance at $610 \mathrm{~nm}$ using a fluorescencespectrum photometer.

The results are presented as the mean \pm standard error. Statistical comparisons between the quantities of Ca ${ }^{2+}$ were performed using two-way unrepeated ANOVA followed by post hoc analysis with the Tukey-Kramer test. Differences of $p<0.01$ were considered significant. 


\section{Results}

\subsection{ALP activity of rDPCs from non-injected rats cultured with MZR}

The ALP activity of rDPCs in the subculture with MZR in 6-well culture plates is shown in Figure 1. The ALP activity of rDPCs cultured without Dex and MZR in MEM as a negative control was $0.040 \pm 0.006 \mu \mathrm{mol} / \mu \mathrm{g}$ of DNA, which was significantly lower than that of rDPCs cultured with Dex and MZR $(p<0.01)$. rDPCs cultured with Dex and $5 \mu \mathrm{g}, 500 \mathrm{ng}$ rDPCs cultured with Dex and $5 \mu \mathrm{g}, 500 \mathrm{ng}$ or $50 \mathrm{ng}$ of MZR had significantly higher ALP activity values than those cultured with Dex alone. With Dex and $50 \mu \mathrm{g}$ of MZR, the ALP activity of rDPCs was not significantly different from the culture with Dex but without MZR. ALP activity was significantly higher in the rDPCs cultured with Dex and MZR at $5 \mu \mathrm{g}$ or less.

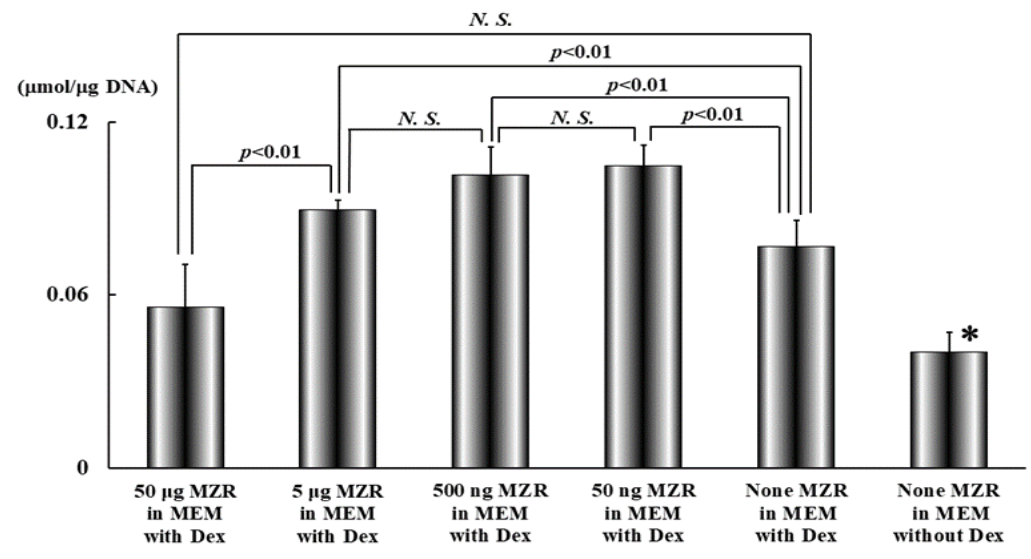

Figure 1 ALP activity of cultured rDPCs from rats without subcutaneous injection of MZR

ALP activity of rDPCs cultured without Dex and MZR in MEM as a negative control was significantly lower than that of rBMCs cultured with Dex and MZR $(p<0.01)$. Significantly higher ALP activity was observed in the rBMC culture with Dex and MZR at $5 \mu$ or less $(p<0.01)$.

\subsection{ALP activity of cultured rDPCs from rats with and without MZR injection}

The ALP activity of rDPCs from MRZ-injected rats was $0.054 \pm 0.006 \mu \mathrm{mol} / \mu \mathrm{l}$ of DNA in MEM with Dex. The activity level of those from non-injected rats was significantly higher $(p<0.01)$. As shown in Figure 2 , the ALP activity of rDPCs from rats injected with MZR cultured with Dex was significantly lower at $0.077 \pm 0.009 \mu \mathrm{mol} / \mu \mathrm{l}$ of DNA than that of rDPCs from rats without MZR injection.

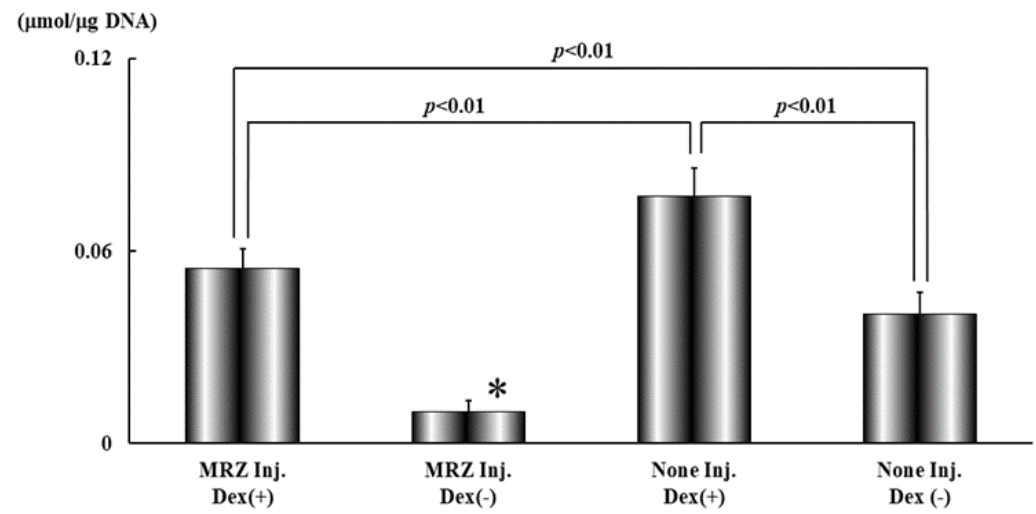

Figure 2 ALP activity of cultured rDPCs from rats with and without subcutaneous injection of MZR

rDPCs from MZR-injected rats had high ALP activity. The activity level of cells from non-injected rats was significantly higher $(p<0.01)$. In MEM with Dex, rDPCs from rats injected with MZR had significantly lower ALP activity than those from rats without MZR injection at $0.077 \pm 0.009 \mu \mathrm{mol} / \mu \mathrm{l}$ DNA $(p<0.01)$. 


\subsection{Effects of MZR in culture medium on calcified nodule deposition by rDPCs from rats without MZR injection}

The addition of MZR to the subculture of rDPCs from non-injected rats suppressed the hard tissue-forming effects of Dex. As shown in Figure 3, rDPCs from non-injected rats cultured with Dex produced a significantly low amount of Ca ${ }^{2+}$ $(p<0.01)$. The amount of $\mathrm{Ca}^{2+}$ produced by rDPCs cultured with Dex alone was $4.115 \pm 0.942 \mathrm{mg} / \mathrm{dl}$, being the highest. The level of $\mathrm{Ca}^{2+}$ produced from nodules of rDPCs in MEM with Dex was significantly higher than that produced in cell culture containing $5 \mu \mathrm{g}$, $500 \mathrm{ng}$ or $50 \mathrm{ng}$ of MZR with Dex.

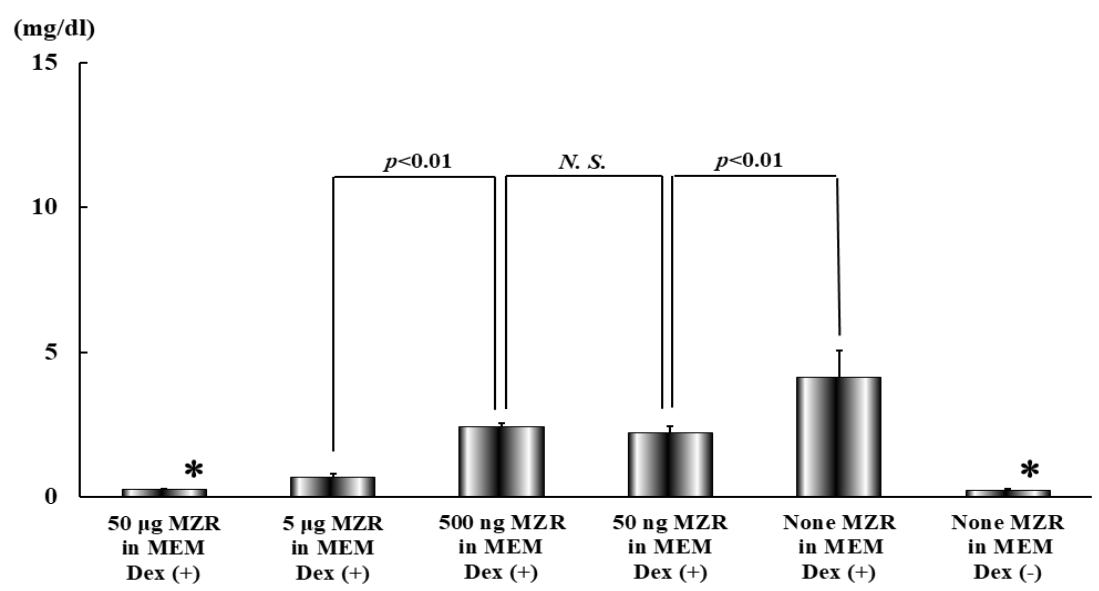

Figure 3 In the culture with MZR, the amount of $\mathrm{Ca}^{2+}$ from decalcified nodules formed by rDPCs from rats without subcutaneous injection of MZR

The amount of $\mathrm{Ca}^{2+}$ obtained from calcified nodules formed by rDPCs in MEM with Dex and $50 \mu \mathrm{g}$ of MZR or without Dex was significantly low $(p<0.01)$. On the other hand, the amount of $\mathrm{Ca}^{2+}$ produced by rDPCs cultured with Dex was significantly high.

\subsection{Comparison of $\mathrm{Ca}^{2+}$ amounts from deposited calcified nodules of rDPCs from rats with and without MZR injection}

The quantitative analysis of $\mathrm{Ca}^{2+}$ revealed that many calcified nodules had been formed in the subculture of rDPCs from the rats subcutaneously injected with MZR, as shown in Figure 4. In the culture with Dex, rDPCs from MZR-injected rats

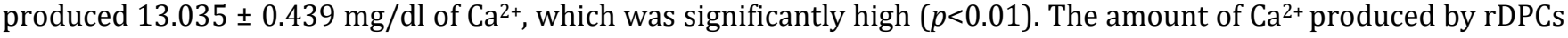
from MZR-injected rats cultured without Dex, $6.423 \pm 0.187 \mathrm{mg} / \mathrm{dl}$, was significantly higher than that produced by those from the rats without MZR injection cultured with Dex.

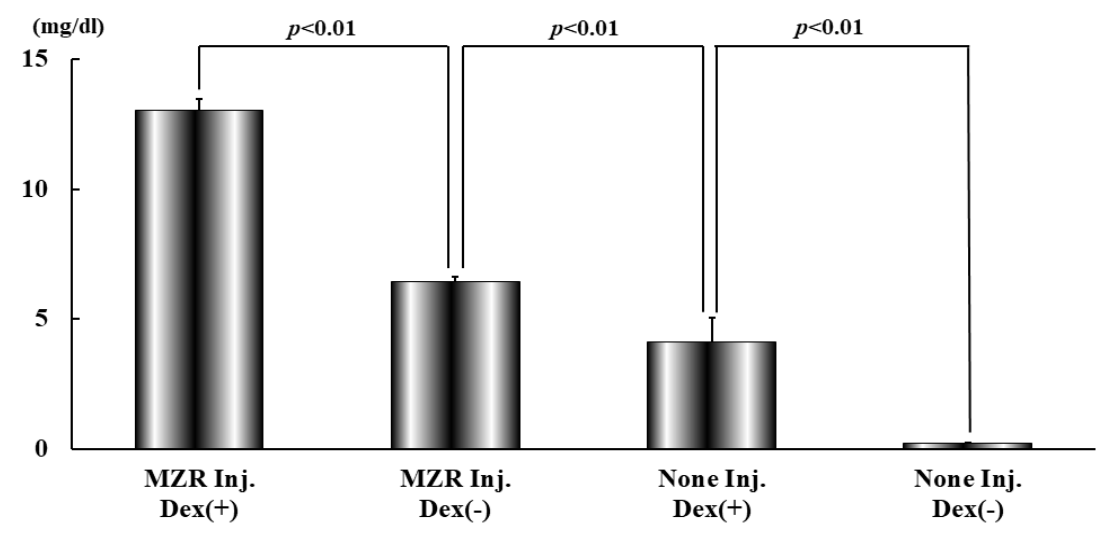

Figure 4 Measurement of $\mathrm{Ca}^{2+}$ amount from calcified nodules in MEM formed by rDPCs from rats with and without subcutaneous injection of MZR

The amount of $\mathrm{Ca}^{2+}$ produced by rDPCs from rats subcutaneously injected with MZR cultured with Dex was significantly high $(p<0.01)$. The amount of $\mathrm{Ca}^{2+}$ was significantly higher in the culture of rDPCs from MZR-injected rats without Dex than that in the culture of rDPCs from non-injected rats with Dex. 


\section{Discussion}

Bone formation can be induced using bone marrow cells obtained from the iliac bones of patients undergoing orthopedic surgery. However, due to the rarity of MSCs [15], several in vitro passages may be required to increase the population of MSCs before experimental usage or clinical application. Many rounds of subculture are necessary for the stem cells in bone marrow to proliferate and differentiate into osteoblasts to induce subsequent hard tissue formation [16]. It was previously reported that the number of MSCs in bone marrow cells is limited [17] and that they only account for 0.001$0.01 \%$ of all nucleated bone marrow cells [18]. Thus, a significant number of bone marrow cells is required for tooth regeneration. According to an in vitro study using rat bone marrow cells, the number of cells required for calcified nodule formation in subculture is $1 \times 10^{5}$ cells per well in a 6-well culture plate [19]. The number of bone marrow cells obtained from one rat femur was approximately 1.0 to $1.6 \times 10^{7}$ cells after primary culture in T-75 flasks for 7-10 days in most of our previous experiments [20, 21, 22]. In the oral cavity, MSCs are present in the dental pulp [23], periodontal ligament [24] and gingiva [25]. The number of stem cells in the dental pulp tissue is small, but dental pulp stem cells have a higher proliferative capacity than bone marrow stem cells [23]. Although regeneration of a tooth or bone using dental pulp-derived stem cells has been reported [26], for bone or tooth regeneration, the stem cells must be proliferated in a large number by primary culture.

In this study, MZR was subcutaneously injected into rats to mildly suppress the systemic immune response. MZR was developed in Japan in 1971 and has purine metabolism antagonistic activity in nucleic acid synthesis systems [27]. It was previously demonstrated to markedly inhibit $\mathrm{T}$ cell proliferation and the expression of $\mathrm{T}$ cell surface activation molecules [28]. MZR may not damage normal cells or nucleic acids [29]. In primary cultures of rDPCs in T-25 flasks, a long time was needed for cells to become confluent. Thus, MZR injected subcutaneously may not affect the proliferation of stem cells in primary culture. However, MZR had significant effects on calcified nodule formation in the subculture of rDPCs by subcutaneous injection, suggesting that it increased the osteogenic ability of the stem cells. The addition of MZR directly to culture medium reduced the amount of produced $\mathrm{Ca}^{2+}$. The effects of Dex and $\beta$-GP were inhibited in an MZR concentration-dependent manner. On the other hand, in the subculture of rDPCs from rats injected with MZR, significantly more $\mathrm{Ca}^{2+}$ was produced with the addition of Dex and $\beta$-GP. Furthermore, in the culture without Dex, significantly higher amounts of $\mathrm{Ca}^{2+}$ were produced by rDPCs from MZR-injected rats than by those from non-injected rats. This suggested that stem cells from rats subcutaneously injected with MZR acquired the ability to regenerate hard tissue in the presence of $\beta-G P$.

MSCs exhibit broad and potent immuno-regulatory effects in vitro and in vivo [30]. It was previously reported that MSCs derived from human bone marrow suppressed the antibody-producing ability and proliferation of B cells [31]. Conversely, there were reports that MSCs can promote B cell proliferation and antibody production [32]. Although several molecules are involved in the molecular mechanism underlying the action of MSCs to suppress immunity, their details are unclear [33]. We focused on the involvement of MSCs in the suppression of systematical immunity [10]. Based on these reports, we hypothesized that stem cells in rDPCs can be increased by suppressing systemic immune responses in the experimental animals. This hypothesis was confirmed in this study.

FK506, an immunosuppressant, was reported to exhibit high osteogenic potential in vivo [34]. The results of an in vivo study were similar to those of this in vitro study. MSCs in the dental pulp may have been stimulated systemically by MZR as a result of subcutaneous injection. Cells stimulated by MZR should rapidly differentiate into osteoblasts after adding Dex and $\beta$-GP in vitro. As interleukin 17 promotes osteoclast differentiation and proliferation, suppressing the activity of Th17 cells by an immunosuppressant should lead to new bone formation [35].

The components in the culture medium to promote cell proliferation should be reconsidered. The direct effect of the agent on rDPCs in this in vitro study was the suppression of calcified nodule formation. However, rDPCs from rats injected with an immunosuppressant before cell harvest demonstrated significant hard tissue formation. Therefore, systemic administration of an immunosuppressant prior to harvesting stem cells from an individual is recommended. For such application, the amount of immunosuppressant for systemic administration must be limited and systemic disadvantages should not be caused by its administration.

\section{Conclusion}

Mizoribine, an immunosuppressant, inhibits the proliferation and differentiation of stem cells. Calcified nodule formation by rDPCs was suppressed by the addition of this immunosuppressant in vitro. On the other hand, rDPCs from rats systemically administered this agent had high osteogenesis capability and acquired the ability to spontaneously deposit calcium. 
To promote the proliferation and differentiation of stem cells, systemic administration of an immunosuppressant to individuals prior to harvesting stem cells is recommended.

\section{Compliance with ethical standards}

\section{Acknowledgments}

This study was performed at the Low-Temperature Facilities at the Tissue Culture Facilities, Laboratory Animal Facilities and Materials Center, Institute of Dental Research, Osaka Dental University. This study was supported in part by 2015-2017 (C: 15K11140) and 2016-2018 (C: 16K11574) Grants-in-Aid for Scientific Research (C) from the Japan Society for the Promotion of Science.

\section{Disclosure of conflict of interest}

All authors declare no conflicts of interest associated with this manuscript.

\section{References}

[1] Oryan A, Kamali A, Moshiri A, Baghaban EM. Role of mesenchymal stem cells in bone regenerative medicine: What is the evidence? Cells Tissues Organs, 2017; 204(2):59-83. https://doi.org/10.1159/000469704

[2] Boskey AL. Mineralization of Bones and Teeth. Elements. 2007; 3(6):385-391. https://doi.org/10.2113/gselements.3.6.385

[3] Ohazama A, Modino SAC, Miletich I, Sharpe PT. Stem-cell-based tissue engineering of murine teeth. J Dent Res. 2004; 83(7):518-522. https://doi.org/10.1177/154405910408300702

[4] Tsujigiwa H, Katase N, Lefeuvre M, Yamachika E, Tamamura R, Ito S, Takebe Y, Matsuda H, Nagatsuka H. Establishment of odontoblastic cells, which indicate odontoblast features both in vivo and in vitro. J Oral Pathol Med. 2013; 42(10):799-806. https://doi.org/10.1111/jop.12080

[5] Durand SH, Flacher V, Roméas A, Carrouel F, Colomb E, Vincent C, Magloire H, Couble M-L, Bleicher F, Staquet MJ, Lebecque S, Farges J-C. Lipoteichoic acid increases TLR and functional chemokine expression while reducing dentin formation in vitro differentiated human odontoblasts, J Immunol. 2006; 176(5):2880-2887. https://doi.org/10.4049/jimmunol.176.5.2880

[6] Sedgley CM, Botero TM. Dental stem cells and their sources. Dent Clin North Am. 2012; 56(3):549-561. https://doi.org/10.1016/j.cden.2012.05.004

[7] Zhang W, Vazquez B, Oreadi D, Yelick PC. Decellularized Tooth Bud Scaffolds for Tooth Regeneration. J Dent Res. 2006; 96(5):516-523. https://doi.org/10.1177/0022034516689082

[8] Iohara K, Murakami M, Takeuchi N, Osako Y, Ito M, Ishizaka R, Utunomiya S, Nakamura H, Matsushita K, Nakashima M. A novel combinatorial therapy with pulp stem cells and granulocyte colony-stimulating factor for total pulp regeneration. Stem Cells Transl Med. 2013; 2(7):521-533. https://doi.org/10.5966/sctm.2012-0132

[9] Liu Y, Wang L, Kikuiri T, Akiyama K, Chen C, Xu X, Yang R, Chen W, Wang S, Shi S. Mesenchymal stem cell-based tissue regeneration is governed by recipient T lymphocyte via IFN- $\gamma$ and TNF- $\alpha$. Nat Med. 2012; 17(12):15941601. https://doi.org/10.1038/nm.2542

[10] Glennie S, Soeiro I, Dyson PJ, Lam EW, Dazzi F. Bone marrow mesenchymal stem cells induce division arrest anergy of activated T cells. Blood. 2005; 105(7):2821-2827. https://doi.org/10.1182/blood-2004-09-3696

[11] Takayanagi H, Kim S, Koga T, Nishina H, Isshiki M, Yoshida H, Saiura A, Isobe M, Yokochi T, Inoue J, Wagner EF, Mak TW, Kodama T, Taniguchi T. Induction and activation of the transcription factor NFATc1 (NFAT2) integrate RANKL signaling in terminal differentiation of osteoclasts. Dev Cell. 2002; 3(6):889-901. https://doi.org/10.1016/s1534-5807(02)00369-6

[12] Chen C, Akiyama K, Wang D, Xu X, Li B, Moshaverinia A, Brombacher F, Sun L, Shi S. mTOR inhibition rescues osteopenia in mice with systemic sclerosis. J Exp Med. 2015; 212(1):73-91. https://doi.org/10.1084/jem.20140643

[13] Yokota S. Mizoribine: Mode of action and effects in clinical use. Pediatr Int. 2002; 44(2):196-198. https://doi.org/10.1046/j.1328-8067.2002.01536.x 
[14] Nakamura G, Homma N, Sakamaki Y, Toyama M, Unno M, Kuroda T, Narita I. Mizoribine as a safe and effective combined maintenance therapy with prednisolone for anti-neutrophil cytoplasmic antibody-associated vasculitis in a hemodialysis patient. CEN Case Rep. 2013; 2(2):139-43. https://doi.org/10.1007/s13730-0120050-1

[15] Li Z, Zhang C, Weiner LP, Zhang Y, Zhong JF. Molecular characterization of heterogeneous mesenchymal stem cells with single-cell transcriptomes. Biotechnol Adv. 31(2):312-317. https://doi.org/10.1016/j.biotechadv.2012.12.003

[16] Augello A, Kurth TB, De Bari C. Mesenchymal stem cells: a perspective from in vitro cultures to in vivo migration and niches. Eur Cell Mater. 2010; 20:121-33. https://doi.org/10.22203/eCM.v020a11

[17] Pittenger MF, Mackay AM, Beck SC, Jaiswal RK, Douglas R, Mosca JD, Moorman MA, Simonetti DW, Craig S, Marshak DR. Multilineage potential of adult human mesenchymal stem cells. Science. 1999; 284(5411):143-147. https://doi.org/10.1126/science.284.5411.143

[18] Jain M, Minocha E, Tripathy NK, Singh N, Chaturvedi CP, Nityanand S. Comparison of the cardiomyogenic potency of human amniotic fluid and bone marrow mesenchymal stem cells. Int J Stem Cells. 2019; 12(3):449-456. https://doi.org/10.15283/ijsc18087

[19] Declercq H, Van den Vreken N, De Maeyer E, Verbeeck R, Schacht E, De Ridder L, Cornelissen M. Isolation, proliferation and differentiation of osteoblastic cells to study cell/biomaterial interactions: comparison of different isolation techniques and source. Biomaterials. 2004; 25(5):757-768. https://doi.org/10.1016/S0142$\underline{9612(03) 00580-5}$

[20] Yoshikawa M, Tsuji N, Shimomura Y, Hayashi H, Ohgushi H. Osteogenesis depending on geometry of porous hydroxyapatite scaffolds. Calcif Tissue Int. 2008; 83(2):139-145. https://doi.org/10.1007/s00223-008-9157-y

[21] Yoshikawa M, Kakigi H, Miyamoto A, Sugimoto S, Nakai K, Ikenaga H, Inamoto T, Maeda H. In vivo estimation of osteogenesis by bone marrow cells in a bi-phasic scaffold and in each of its components. JBiSE. 2016; 9(11):501514. http://dx.doi.org/10.4236/ibise.2016.911045

[22] Miyamoto A, Yoshikawa M, Maeda H. Hard tissue-forming ability and ultra-micro structure of newly developed sponges as scaffolds made with sodium alginate gel and chondroitin sulfate. JbiSE. 2018; 11(11):289-306. https://doi.org/10.4236/ibise.2018.1111024

[23] Gronthos S, Mankani M, Brahim J, Robey PG, Shi S. Postnatal human dental pulp stem cells (DPSCs) in vitro and in vivo. Proc Natl Acad Sci USA. 2000; 97(25):13625-13630. https://doi.org/10.1073/pnas.240309797

[24] Seo BM, Miura M, Gronthos S, Bartold PM, Batouli S, Brahim J, Young M, Robey PG, Wang CY, Shi S. Investigation of multipotent postnatal stem cells from human periodontal ligament. Lancet. 2004; 364(9429):149-155. https://doi.org/10.1016/S0140-6736(04)16627-0

[25] Grawish ME. Gingival-derived mesenchymal stem cells: An endless resource for regenerative dentistry. World J Stem Cells. 2018; 10(9):116-118. https://dx.doi.org/10.4252/wjsc.v10.i9.116

[26] Tatullo M, Marrelli M, Shakesheff KM, White LJ. Dental pulp stem cells: function, isolation and applications in regenerative medicine. J Tissue Eng Regen Med. 2015; 9(11):1205-16. https://doi.org/10.1002/term.1899

[27] Nakajo A, Khoshnoodi J, Takenaka H. Mizoribine corrects defective nephrin biogenesis byrestoring intracellular energy balance. J Am Soc Nephrol. 2007; 18:2554-2564. https://doi.org/10.1681/ASN.2006070732

[28] Turka LA, Dayton J, Sinclair G, Thompson CB, Mitchell BS. Guanine ribonucleotide depletion inhibits T cell activation. Mechanism of action of the immunosuppressive drug Mizoribine. J Clin Invest. 1991; 87(3):940-948. https://doi.org/10.1172/ICI115101

[29] Yamashita M, Saito T, Ise K, Ishii S, Satoh Y, Saito T, Oshibe I, Shimizu H, Kenjo A, Kimura T, Gotoh M. Mizoribine as sole immunosuppressive agent in islet xenotransplantation models: a candidate immunosuppressant causing no adverse effects on islets. 2012.;Cell Transplant 2012 21(2-3):535-545. http://dx.doi.org/10.3727/096368911X605457

[30] Fazekasova HH, Lechler RR, Langford KK, Lombardi GG. Placenta-derived MSCs are partially immunogenic and less immuno modulatory than bone marrow-derived MSCs. J Tissue Eng Regen Med. 2011; 5(9):684-694. https://doi.org/10.1002/term.362 
[31] Corcione A, Benvenuto F, Ferretti E, Giunti D, Cappiello V, Cazzanti F, Marco Risso M, Gualandi F, Mancardi GL, Pistoia V, Uccelli A. Human mesenchymal stem cells modulate B-cell functions. Blood 2006; 107(1):367-372. https://doi.org/10.1182/blood-2005-07-2657

[32] Traggiai E, Volpi S, Schena F, Gattorno M, Ferlito F, Moretta L, Martini A. Bone marrow-derived mesenchymal stem cells induce both polyclonal expansion and differentiation of B cells isolated from healthy donors and systemic lupus erythematosus patients. Stem Cells. 2008; 26(2):562-569. https://doi.org/10.1634/stemcells.2007-0528

[33] Sato K, Ozaki K, Oh I, Meguro A, Hatanaka K, Nagai T, Muroi K. Ozawa K. Nitric oxideplays a critical role in suppression of $\mathrm{T}$ cell proliferation by mesenchymal stem cells. Blood. 2007; 109(1):228-234. https://doi.org/10.1182/blood-2006-02-002246

[34] Yoshikawa T, Nakajima H, Yamada E, Akahane M, Dohi Y, Ohgushi H, Tamai S, Ichijima K. In vivo osteogenic capability of cultured allogeneic bone in porous hydroxyapatite: Immunosuppressive and osteogenic potential of FK506 in vivo. J Bone Miner Res. 2000; 15(6):1147-1157. https://doi.org/10.1359/jbmr.2000.15.6.1147

[35] Yago T, Nanke Y, Kawamoto M, Yamanaka H, Kotake S. Tacrolimus potently inhibits human osteoclastogenesis induced by IL-17 from human monocytes alone and suppresses human Th17 differentiation. Cytokine. 2012; 59(2):252-257. https://doi.org/10.1016/j.cyto.2012.04.012 